\title{
The effect of oil palm agricultural expansion on group size of long-tailed macaques (Macaca fascicularis) in Peninsular Malaysia.
}

\begin{abstract}
Large-scale expansion of oil palm (Elaeis guineensis) monocultures across Southeast Asia are creating ecosystems with homogenous habitats with low species diversity. However, heterogeneity varies between oil palm smallholdings and large-scale plantations, with greater habitat heterogeneity found on smallholdings. To date, there has been a paucity of field research on primate species, particularly macaques in oil palm plantations. In this study, we investigate the group size of long-tailed macaques (Macaca fascicularis) in four habitat types: unlogged forest, logged forest, large-scale oil palm plantations, and smallholdings. Field censuses were conducted in 2015 and 2016 to determine the group size of M. fascicularis in large-scale oil palm plantations and oil palm smallholdings. These data from oil palm plantations were compared to surveys conducted on a logged lowland forest reserve and a previous study in an unlogged lowland forest. We found that group size of M. fascicularis in large-scale plantations was lower compared to smallholdings, logged forest and unlogged forest. The chi-square test showed that the age class (juvenile or adult) of $\mathrm{M}$. fascicularis was associated with farming systems. The paper concludes that the expansion of large-scale oil palm monocultures should be limited because of its adverse impacts on biodiversity including common species such as M. fascicularis.
\end{abstract}

Keyword: Large-scale plantation; Logged forest; Long-tailed macaque; Oil palm; Smallholdings; Unlogged forest. 